\title{
All in one, a rare case presentation of genitourinary tuberculosis
}

\author{
Vishwajeet Singh, Manoj Kumar, S. K. Pavan Kumar ${ }^{*}$ (D) and Mayank Jain
}

\begin{abstract}
Background: The kidneys are the most common site of urogenital tuberculosis. Tuberculosis of the urethra and bladder is caused by a descending infection through the urinary collecting system. Urogenital tuberculosis affects $2 \%$ to $10 \%$ of pulmonary tuberculosis cases in developed countries, but 15\% to 20\% in developing countries.

Case presentation: A 55-year-old male referred to us with bilateral percutaneous nephrostomy, which was done for obstructive uropathy with raised creatinine of $4.5 \mathrm{mg} / \mathrm{dl}$. He was diagnosed with pulmonary tuberculosis two years back and took antitubercular therapy for one year. His routine blood parameters were within normal limits. On evaluation with bilateral nephrostograms, he was found to have right-sided pelvic ureteric junction stricture and left-sided vesicoureteric junction stricture. On retrograde urethrography, there was evidence of 4-cm stricture at proximal bulbar urethra. On contrast-enhanced CT whole abdomen, he was found to have small-sized right kidney and findings in par with nephrostogram with thickened, small capacity bladder (thimble bladder). Patient underwent urethroscopy and urethral dilatation followed by augmentation ileocystoplasty with left ureteric reimplantation and right nephrectomy done at 3 months of follow-up.

Conclusion: Only 1.9 percent to 4.5 percent of all cases of urogenital tuberculosis are urethral tuberculosis, and it never happens alone. For urogenital tuberculosis diagnosis, imaging techniques are up to 91.4 percent sensitive, with intravenous urography and abdominal computerised tomography being the most widely used. Diagnosis relies on a range of signs such as "caliceal irregularities; infundibular stenosis; pseudotumor or renal scarring; nonfunctioning kidney; renal cavitation; urinary tract calcification (present in 7\% to 19\% of cases); collecting system thickening, stenosis, or dilatation; contracted bladder".
\end{abstract}

\section{Background}

The most virulent mycobacterium pathogen to humans is mycobacterium tuberculosis, an acid fast aerobic bacillus. Its slow replication rate explains both the infection's stealthiness and its resistance to common antibiotics, which function during bacterial division. Although the bacillus can remain dormant for a long time without causing symptoms, reactivation can occur following decrease in immunity [1]. Primary tuberculosis of the lungs is usually asymptomatic. Bacillemia spreads from this pulmonary focus to other tissues, resulting in bacillus implantation. Colonisation of the renal and prostate

${ }^{*}$ Correspondence: Pavan53rame@gmail.com

Department of Urology, King George's Medical University, Lucknow, India parenchyma may occur at this point. After 6 months, the patient experiences spontaneous cicatrisation of primary pulmonary tuberculosis and enters a latent phase, with a $5 \%$ chance of disease reactivation in the next 2 years and a $5 \%$ chance of lifetime reactivation. After a decline in immunity induced by malnutrition, diabetes mellitus, steroid usage, immunosuppressant use, and immunodeficiency, latent foci reactivated in the majority of active cases of both pulmonary and extrapulmonary disease [2].

Even in developed countries where tuberculosis was previously uncommon, the AIDS epidemic resulted in unexpected global levels of tuberculosis. When compared to patients in other countries, patients with urogenital tuberculosis in developed countries have fewer specific symptoms and a lower rate of delayed diagnosis. 
In autopsy studies, only $50 \%$ of patients with renal tuberculosis were symptomatic, and only $18 \%$ had received a clinical diagnosis. As a result, the disease is less serious, with more patients presenting with no significant upper urinary tract lesions at the time of diagnosis [3].

\section{Case presentation}

A 55-year-old male was referred to our outpatient clinic with bilateral percutaneous nephrostomy (PCN) done elsewhere in view of acute renal failure secondary to obstructive uropathy 3 months back. Patient had a history of pulmonary tuberculosis 2 years back for which he took 1 year course of ATT (diagnosed and treated elsewhere). He was having history of urinary frequency, urgency and dysuria prior to anuria. His routine blood investigation including haemoglobin $(12.5 \mathrm{gm})$, total leucocytes (7400cells/cumm), kidney function tests (urea 32 and creatinine $1.1 \mathrm{mg} / \mathrm{dl}$ ) and liver function tests was within normal limits. His urine for acid fast bacillus was negative, and his chest X-ray revealed no abnormality. On evaluation with contrast-enhanced CT urography, he was found to have right small kidney $(6.2 \times 5 \mathrm{~cm})$ with pelvic-ureteric junction obstruction with left-sided mild hydroureteronephrosis with complete cut-off at vesicoureteral junction with thickened small capacity bladder (Figs. 1,2). On bilateral nephrostogram, he was found to have right-sided pelvic-ureteric junction obstruction and left-sided vesicoureteral junction obstruction with no contrast opacification of bladder (Figs. 3, 4). On urethroscopy, he was found to have multiple false passage at the level of proximal bulbar urethra. On retrograde urethrography, there is evidence of stricture at proximal bulbar urethra (Fig. 5). In view of all the above findings, a provisional diagnosis of genitourinary tuberculosis was made.

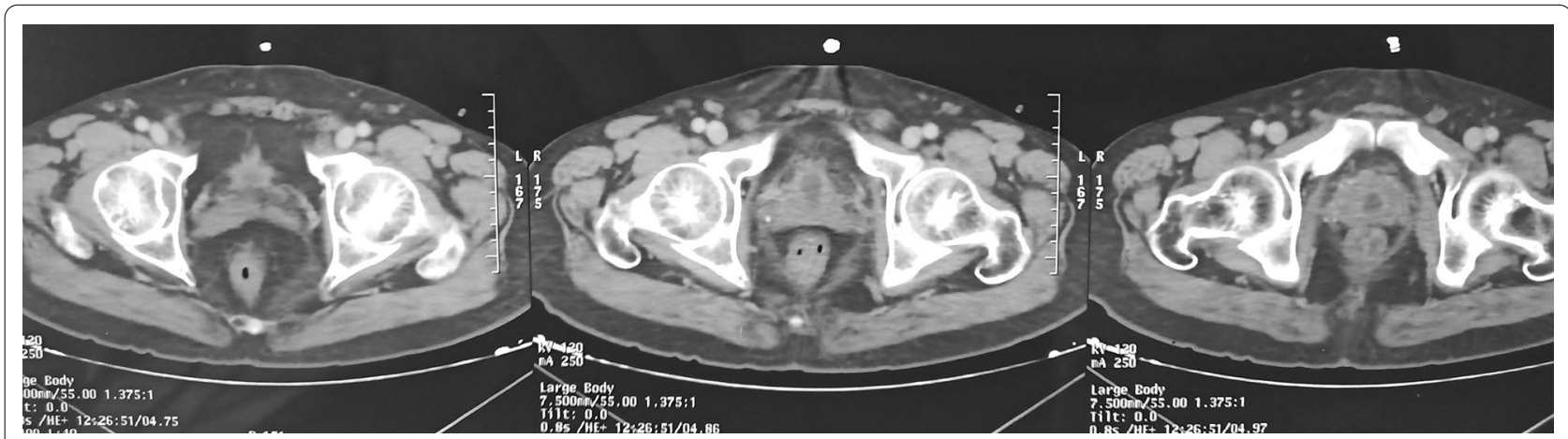

Fig. 1 CECT whole abdomen showing right small kidney and left normal kidney with bilateral PCN in situ with thimble bladder

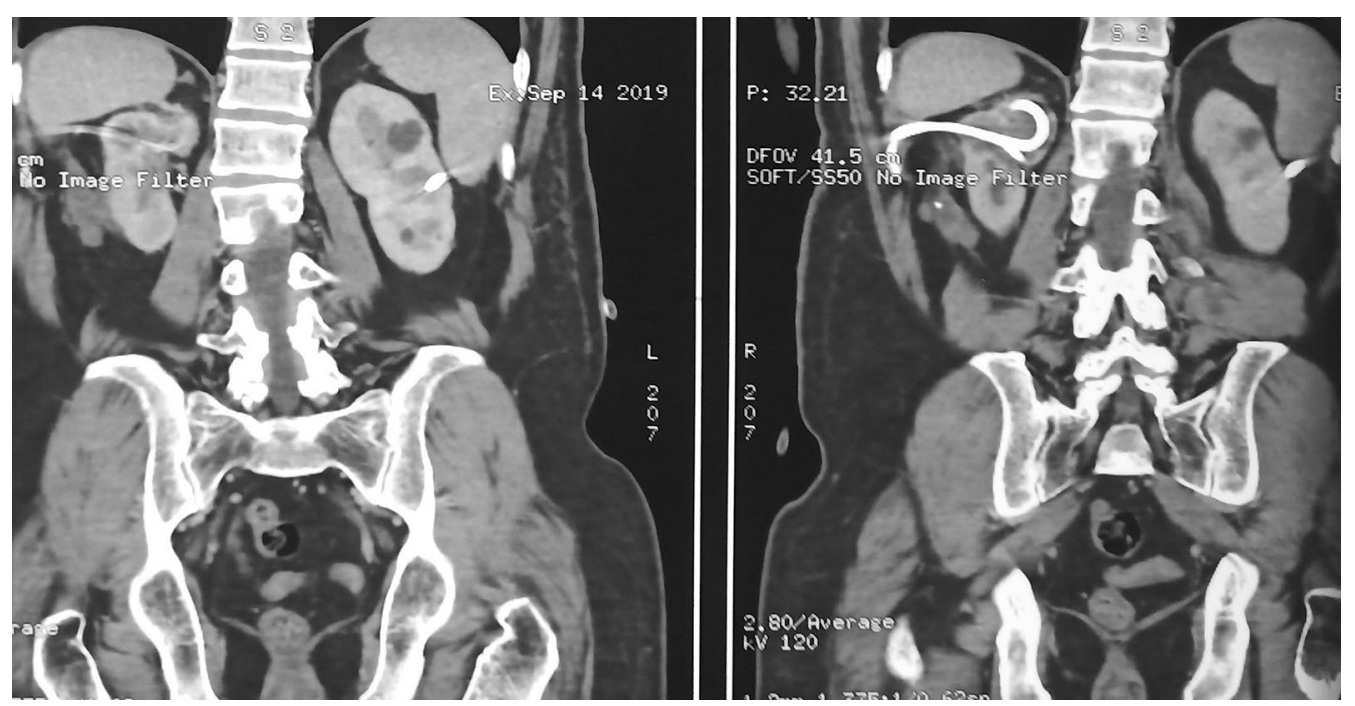

Fig. 2 CECT whole abdomen showing right small kidney and left normal kidney with bilateral PCN in situ with thimble bladder 


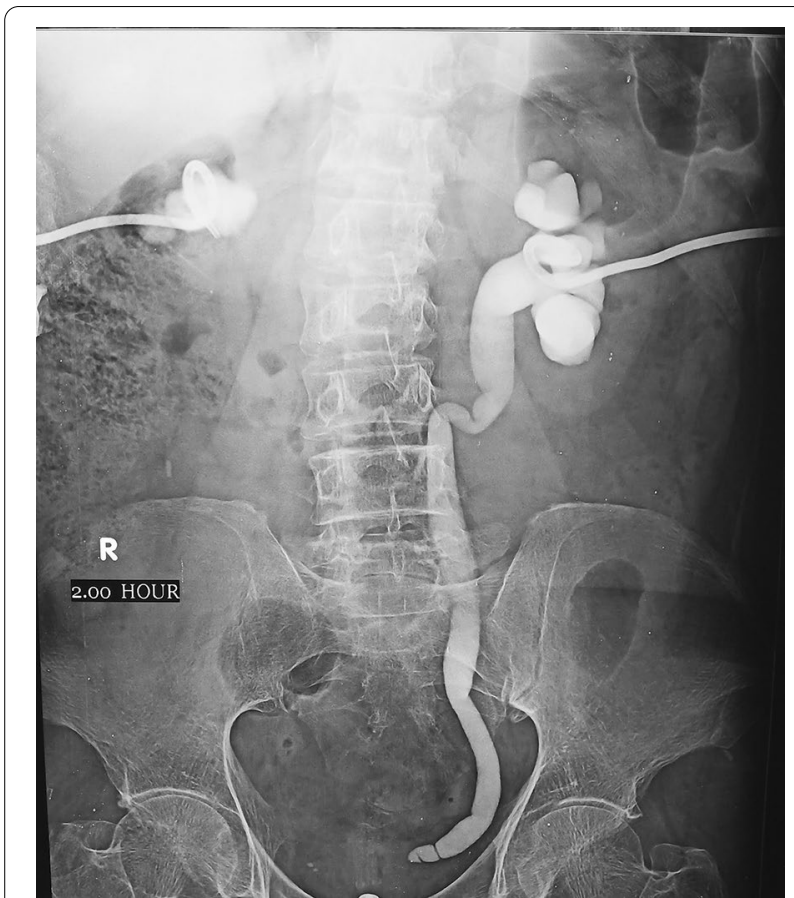

Fig. 3 Bilateral nephrostogram showing Rt pelvic junction obstruction and left vesicoureteric junction obstruction with no evidence of contrast in the bladder

\section{Treatment}

Initially patient underwent urethroscopy and 0.035$\mathrm{mm}$ terumo guidewire negotiation through the stricture followed by sequential dilatation with Teflon dilators ranging with size from 6 to $18 \mathrm{fr}$. After 10 days, he underwent rigid cystoscopy with $16 \mathrm{fr}$ sheath for the assessment of bladder capacity and continence. Diluted urografin contrast was instilled into the bladder under fluoroscopic guidance for the assessment of his bladder capacity, which was around $10 \mathrm{ml}$, and there was no leak of contrast from bladder neck, which confirmed the patient was continent. After proper counselling and consent, patient was taken for augmentation ileocystoplasty in elective OT. Intraoperatively there was evidence of thickened small capacity bladder (Figs. 6, 7). Ileal segment measuring around $40 \mathrm{~cm}$ long located $25-40 \mathrm{~cm}$ from the ileocaecal valve is refashioned to a wide plate and sutured to bladder margins (Figs. 8, 9, 10, 11) with left ureteric reimplantation (Fig. 12). His right kidney was small, and daily output from $\mathrm{PCN}$ was 100 to $150 \mathrm{ml}$; hence, decision for leave it as such was considered. Later, right-sided nephrectomy was done after 3 months.

\subsection{Outcomes and follow-up}

At his 3-month follow-up, patient was healthy and doing fine with minimally elevated serum creatinine of $1.7 \mathrm{mg} / \mathrm{dl}$. He underwent renal scan at the same followup, which showed minimal functioning right kidney (GFR-8 $\mathrm{ml} / \mathrm{min}$ ) following which he underwent elective right nephrectomy. Histopathology examination of right kidney and lower ureter revealed non-specific chronic inflammation. At his 6-month follow-up, patient is doing clean intermittent catheterisation once a day with no other complaints and with serum creatinine of $1.3 \mathrm{mg} / \mathrm{dl}$.

\section{Discussion}

Renal infection is asymptomatic, slow-moving, and highly destructive, with unilateral renal exclusion and renal failure being reported as early as diagnosis $[4,5]$. Kidney failure can be caused by the progression of a focal lesion, which includes caseous granuloma formation, fibrosis, and renal cavitations, or by obstruction of the urinary collecting system, which is more common [6-9]. The latter may be distal when due to ureteral stenosis or proximal when there are intrarenal stenosis [10]. Tuberculosis of the urethra and bladder is caused by a descending infection through the urinary collecting system. Ureteral tuberculosis was discovered in kidneyinoculated pigs with total ureter occlusion in an experimental study [9]. Multiple stenoses develop throughout the ureter in ureteral tuberculosis, with a predominance in the vesicoureteral junction $[4,5,11]$. In tuberculosis, ureteral stenosis is the most common cause of renal exclusion, accounting for up to 93.7 percent of cases. In bladder tuberculosis, an acute inflammatory process with hyperemia, ulceration, and tubercle formation near the ureteral meatus occurs, followed by bladder wall fibrosis $[1,4,5]$. Given frequent urethral exposure to urinary bacilli, urethral tuberculosis occurs in just 1.9 percent to 4.5 percent of all urogenital tuberculosis cases and never as a standalone individual. The most common clinical presentations are acute urethritis with prostate tuberculosis, urethral stenosis, and fistulae [12, 13].

Because it provides results in 24 to $48 \mathrm{~h}$ and allows for diagnosis even when there are few bacilli, the polymerase chain reaction for $M$ tuberculosis identification in urine has become the ideal diagnostic method. It was 95.6 percent sensitive and 98.1 percent precise as opposed to society. It was 94.3 percent sensitive and 85.7 percent precise as opposed to bacteriologic, histologic, or clinicoradiologic diagnoses [14, 15].

For urogenital tuberculosis diagnosis, imaging techniques are up to 91.4 percent sensitive, with intravenous urography and abdominal computerised tomography 


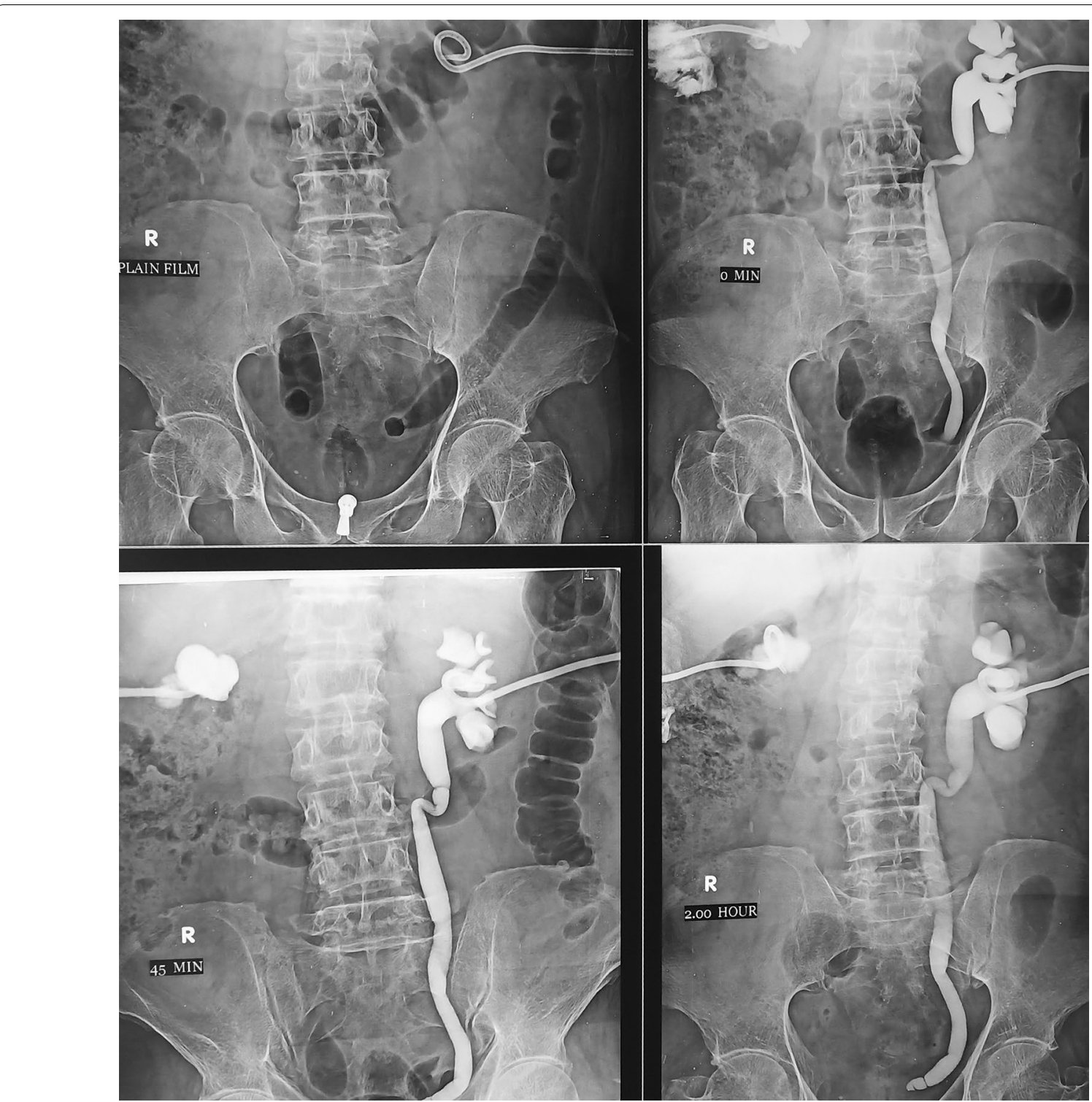

Fig. 4 Bilateral nephrostogram showing Rt pelvic junction obstruction and left vesicoureteric junction obstruction with no evidence of contrast in the bladder

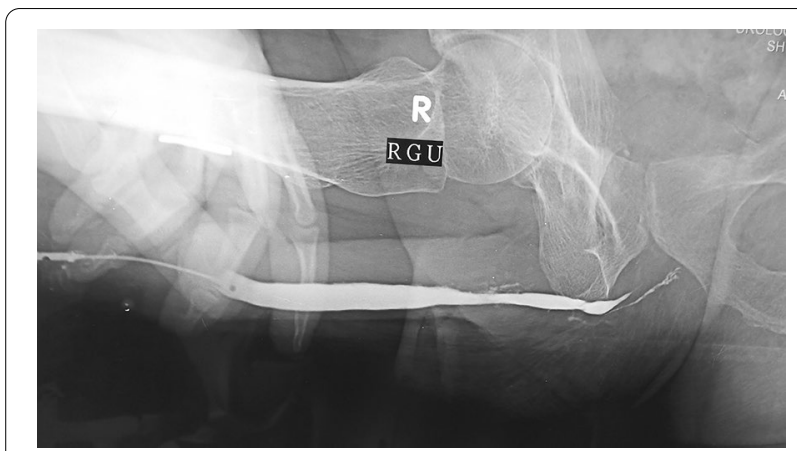

Fig. 5 Retrograde urethrography showing stricture at bulbar urethra being the most widely used. "Caliceal abnormalities, infundibular stenosis, pseudotumor or renal scarring, nonfunctioning kidney, renal cavitation, and urinary tract calcification are all symptoms of urogenital tuberculosis; collecting system thickening, stenosis, or dilatation; contracted bladder; and lesions in other organs beyond the urinary tract, such as lymph nodes, spleen, liver, and vertebrae" [17]. The development of kidney and bladder lesions at the same time is a characteristic of tuberculosis, with outline irregularity and caliceal dilatation due to infundibular stenosis being the first symptoms. Multiple stenoses of the collecting system 

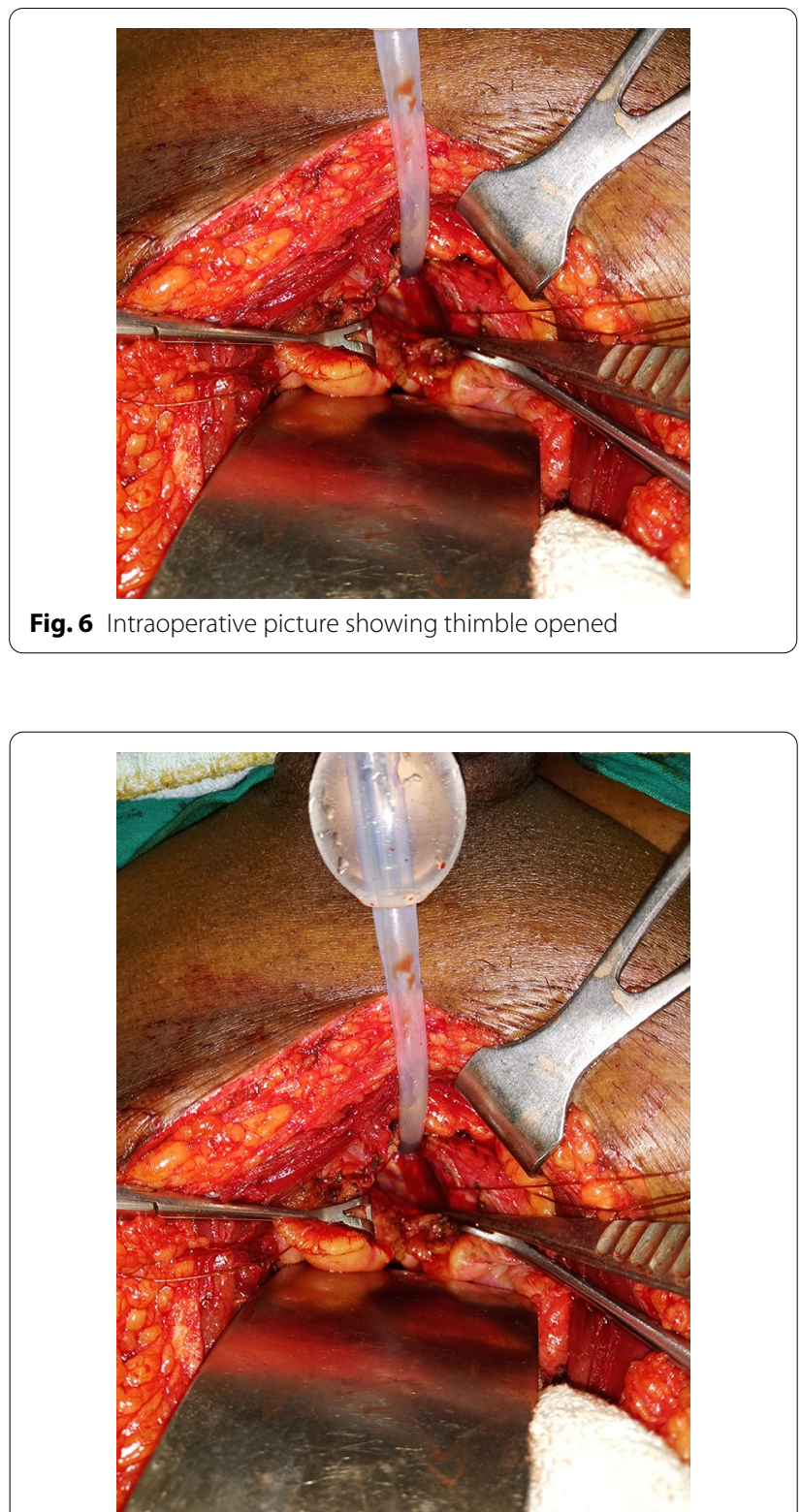

Fig. 7 Intraoperative picture showing thimble Bladder opened

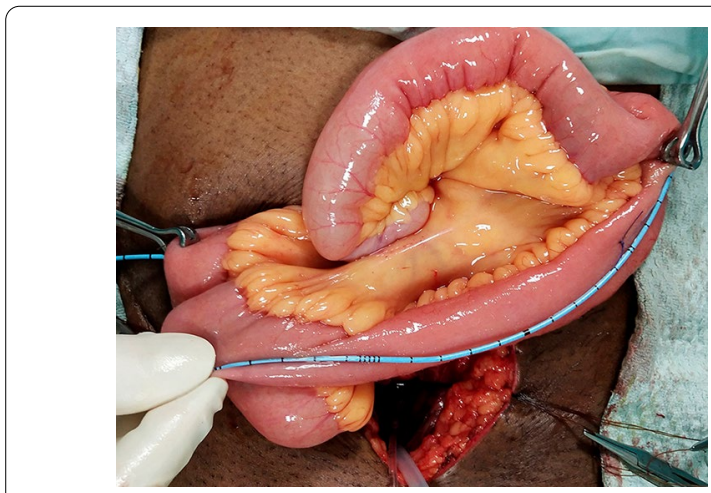

Fig. 8 Augmentation using ileum
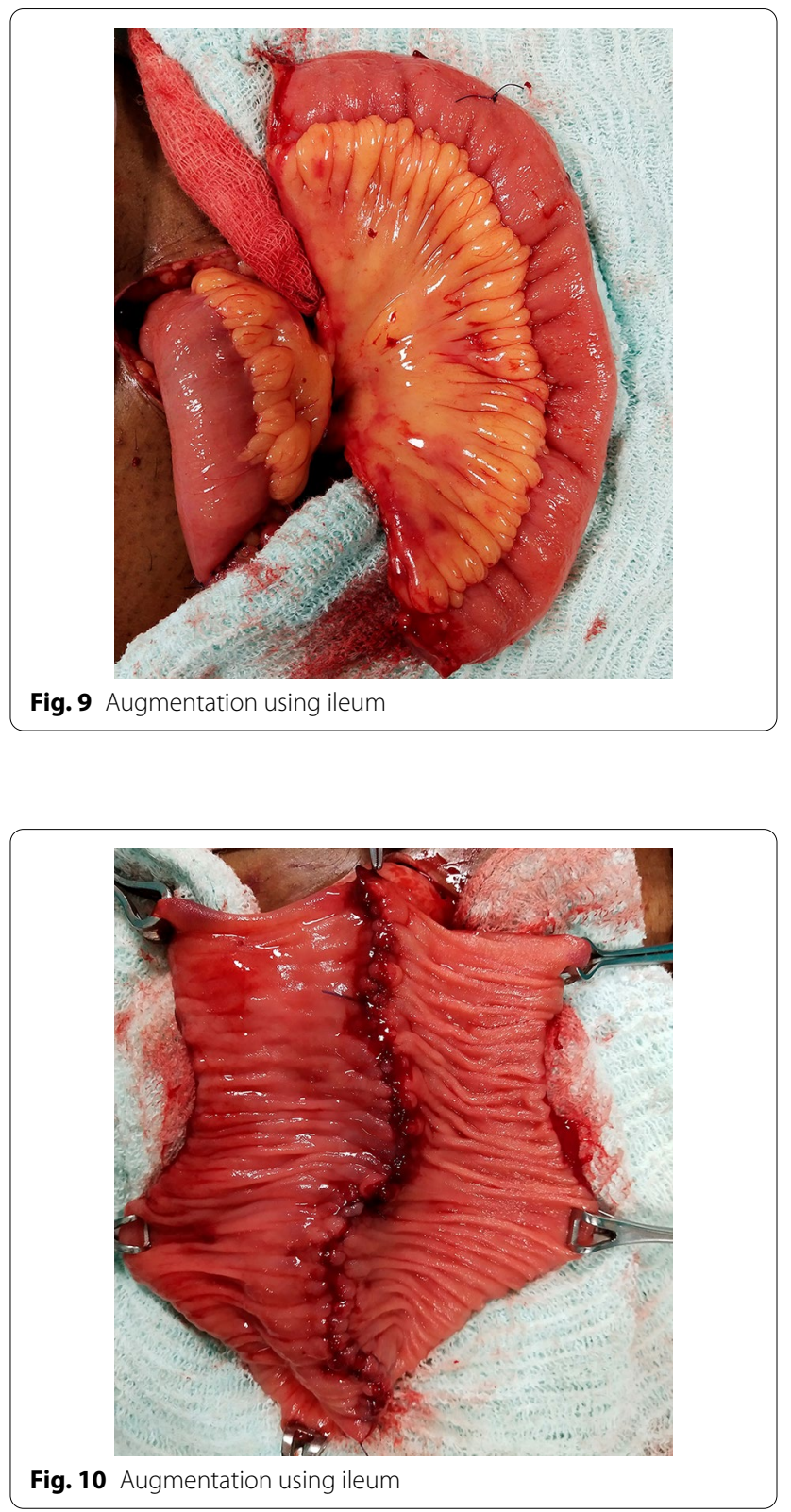

from the infundibulum to the ureterovesical junction, which occur in 60 percent to 84 percent of cases, are the most suggestive of urogenital tuberculosis. The most common and characteristic radiologic finding in tuberculosis patients with a contracted bladder is unilateral nonfunctioning kidney, contracted bladder and vesicoureteral reflux into the functional contralateral kidney [17].

As we can see from our case, there is evidence of right-sided small kidney with upper ureteric stricture and left-sided lower ureteric stricture and contracted small bladder with capacity of $10 \mathrm{ml}$ and proximal 

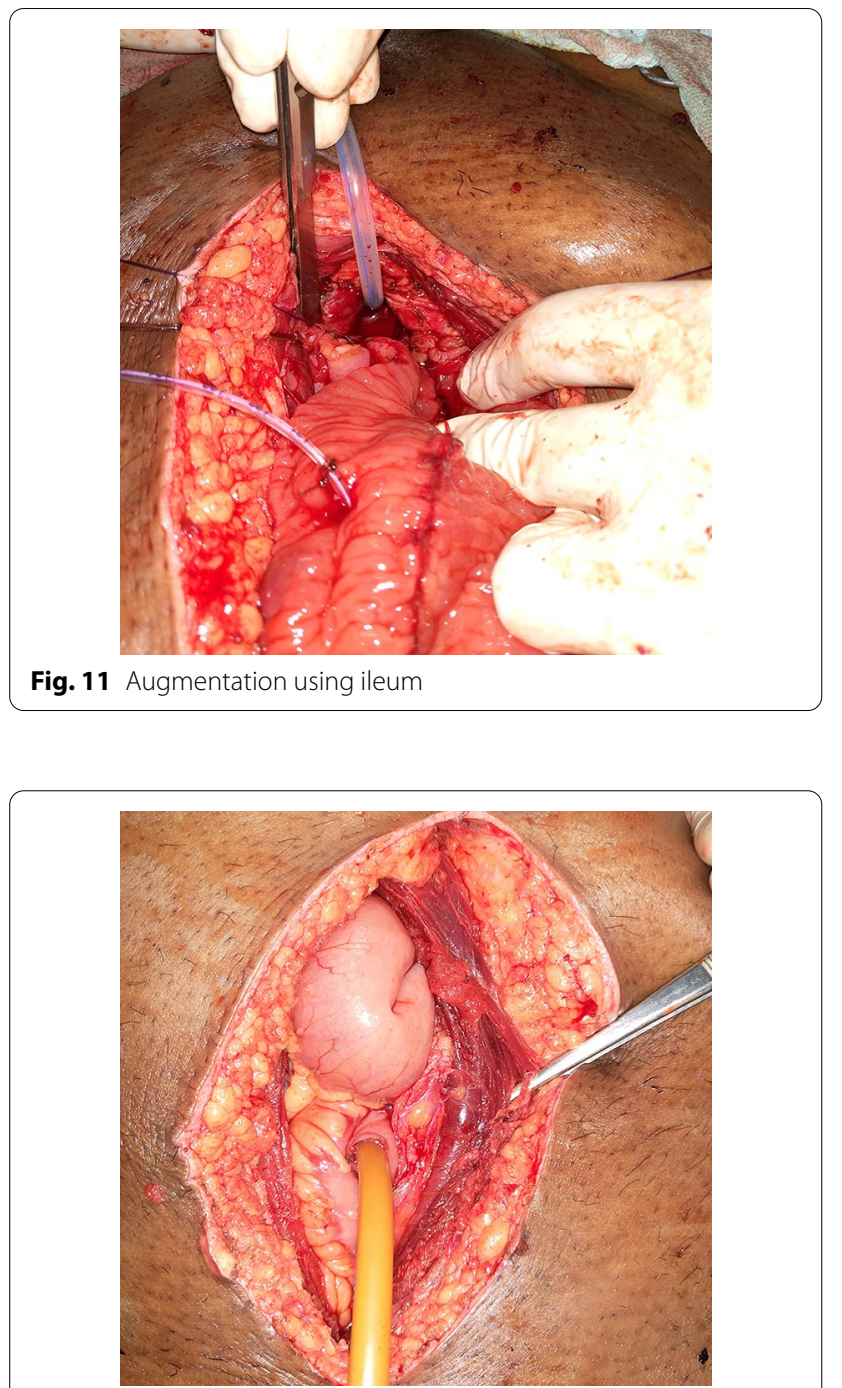

Fig. 12 Completed anastomosis with SPC in situ

bulbar urethral stricture with multiple false passage, all are the sequelae of tuberculosis.

$8.9 \%$ of patients with urogenital tuberculosis have bladder wall fibrosis, which causes capacity loss and increased micturition frequency [1]. "Although some researchers have recorded promising results with complete cystectomy or cystoprostatectomy and orthotopic ileal neobladder to prevent stenosis of the enterovesical anastomosis and enhance pain control, bladder augmentation is the recommended treatment for tuberculosis-related contracted bladder" [16, 17]. The bladder has been supplemented by the stomach, ileum, and colon [18]. In our situation, we used ileum to augment the small contracted bladder. In a study of 25 patients who had bladder augmentation with ileum, sigmoid, or ileocecal segments, no single segment was found to be superior; the option is up to the surgeon [8]. The bowel section may either be used in its tubular form or detubularised to provide more space and lower reservoir pressure [17]. The ileum is actually the most widely used section for bladder augmentation due to its ease of handling. Since ureteral reimplantation is frequently needed in tuberculosis cases, sigmoid and ileocecal segments are frequently used [18].

\section{Conclusion}

When compared to patients in other countries, patients with urogenital tuberculosis in developing countries have less specific symptoms and a lower incidence of delayed diagnosis. Just 1.9 percent to 4.5 percent of all cases of urogenital tuberculosis are urethral tuberculosis, and it never happens alone. For urogenital tuberculosis diagnosis, imaging techniques are up to 91.4 percent sensitive, with intravenous urography and abdominal computerised tomography being the most widely used. Diagnosis relies on a range of signs such as "caliceal irregularities; infundibular stenosis; pseudotumor or renal scarring; nonfunctioning kidney; renal cavitation; urinary tract calcification (present in $7 \%$ to $19 \%$ of cases); collecting system thickening, stenosis, or dilatation; contracted bladder" [17]. The most common and characteristic radiologic finding in tuberculosis patients with a contracted bladder is unilateral nonfunctioning kidney, contracted bladder, and vesicoureteral reflux into the functional contralateral kidney.

\section{Abbreviations}

ATT: Antitubercular therapy; CT: Computed tomography; PCN: Percutaneous nephrostomy; CECT: Contrast-enhanced CT; OT: Operation theatre.

\section{Acknowledgements}

None.

\section{Authors' contributions}

PSK was involved in conception and conduct, and acquisition of data. VJS performed analysis and interpretation and reporting. MK reviewed the literature. $\mathrm{MJ}$ done critical review. All authors have read and approved the manuscript, and they ensure that this is the case.

\section{Funding}

The authors declare that this study has received no financial support.

\section{Availability of data and material}

All data generated or analysed during this study are included in this published article [Urogenital Tuberculosis: Update and Review of 8961 Cases from the World Literature André A. Figueiredo, MD, PhD, Antônio M. Lucon, MD, PhD[Rev Urol. 2008;10(3):207-217]].

\section{Declarations}

Ethics approval and consent to participate

Approval and consent to participate was taken from the ethical committee of the institution. 


\section{Consent for publication}

Written informed consent for the publication of his clinical history and radiological images has been obtained from the patient himself.

\section{Competing interests}

The authors declare no competing interest.

Received: 19 May 2020 Accepted: 30 March 2021

Published online: 09 April 2021

\section{References}

1. Gow JG (1998) Genitourinary tuberculosis. In: Walsh PC, Retik AB, Vaughan ED, Wein AJ (eds) Campbell's urology, 7th edn. W.B. Saunders Company, Philadelphia, p 807

2. Leite OHM (2001) Tuberculosis. Probl Gen Surg 18:69-78

3. Figueiredo A, Lucon A (2008) Urogenital tuberculosis: update and review of 8961 cases from the world literature. Rev Urol 10:207-217

4. Kerr WK, Gale GL, Peterson KS (1969) Reconstructive surgery for genitourinary tuberculosis. J Urol 101:254-266

5. Medlar EM (1926) Cases of renal infection in pulmonary tuberculosis: evidence of healed tuberculous lesions. Am J Pathol 2:401-411

6. Barrie HJ, Kerr WK, Gale GL (1967) The incidence and pathogenesis of tuberculous strictures of the renal pyelus. J Urol 98:584-589

7. Greenwell TJ, Venn SN, Mundy AR (2001) Augmentation cystoplasty. BJU Int 88:511-525

8. Winblad B, Duchek M (1975) Spread of tuberculosis from obstructed and non-obstructed upper urinary tract. Acta Pathol Microbiol Scand [A] 83:229-236
9. Ramanathan R, Kumar A, Kapoor R, Bhandari M (1998) Relief of urinary tract obstruction in tuberculosis to improve renal function. Analysis of predictive factors. Br J Urol 81:199-205

10. Carl P, Stark L (1997) Indications for surgical management of genitourinary tuberculosis. World J Surg 21:505-510

11. Indudhara R, Vaidyanathan S, Radotra BD (1992) Urethral tuberculosis Urol Int 48:436-438

12. Symes JM, Blandy JP (1973) Tuberculosis of the male urethra. Br J Urol 45:432-436

13. Mochalova TP, Starikov IY (1997) Reconstructive surgery for treatment of urogenital tuberculosis: 30 years of observation. World J Surg 21:511-515

14. Hemal AK, Gupta NP, Rajeev TP et al (2000) Polymerase chain reaction in clinically suspected genitourinary tuberculosis: comparison with intravenous urography, bladder biopsy, and urine acid fast bacilli culture. Urology 56:570-574

15. Moussa OM, Eraky I, El-Far MA et al (2000) Rapid diagnosis of genitourinary tuberculosis by polymerase chain reaction and non-radioactive DNA hybridization. J Urol 164:584-588

16. Hemal AK, Aron M (1999) Orthotopic neobladder in management of tubercular thimble bladders: initial experience and long-term results. Urology 53:298-301

17. Ytton B, Green D (1989) Urodynamic studies in patients undergoing bladder replacement surgery. J Urol 141:1394-1397

18. Dounis A, Abel BJ, Gow JG (1980) Cecocystoplasty for bladder augmentation. J Urol 123:164-167

\section{Publisher's Note}

Springer Nature remains neutral with regard to jurisdictional claims in published maps and institutional affiliations.

\section{Submit your manuscript to a SpringerOpen ${ }^{\circ}$ journal and benefit from:}

- Convenient online submission

- Rigorous peer review

- Open access: articles freely available online

- High visibility within the field

- Retaining the copyright to your article

Submit your next manuscript at $\boldsymbol{\nabla}$ springeropen.com 